\title{
Muséologies
}

Les cahiers d'études supérieures

\section{Voici le numéro deux}

\section{Alessandra Mariani}

Volume 1, numéro 2, avril 2007

URI : https://id.erudit.org/iderudit/1033605ar

DOI : https://doi.org/10.7202/1033605ar

Aller au sommaire du numéro

Éditeur(s)

Association Québécoise de Promotion des Recherches Étudiantes en Muséologie (AQPREM)

ISSN

1718-5181 (imprimé) 1929-7815 (numérique)

Découvrir la revue

Citer ce document

Mariani, A. (2007). Voici le numéro deux. Muséologies, 1(2), 6-7. https://doi.org/10.7202/1033605ar

Ce document est protégé par la loi sur le droit d'auteur. L’utilisation des services d'Érudit (y compris la reproduction) est assujettie à sa politique d'utilisation que vous pouvez consulter en ligne.

https://apropos.erudit.org/fr/usagers/politique-dutilisation/
Cet article est diffusé et préservé par Érudit.

Érudit est un consortium interuniversitaire sans but lucratif composé de l’Université de Montréal, l'Université Laval et l'Université du Québec à Montréal. Il a pour mission la promotion et la valorisation de la recherche. https://www.erudit.org/fr/ 


\section{Mot de l'éditeur}

\{

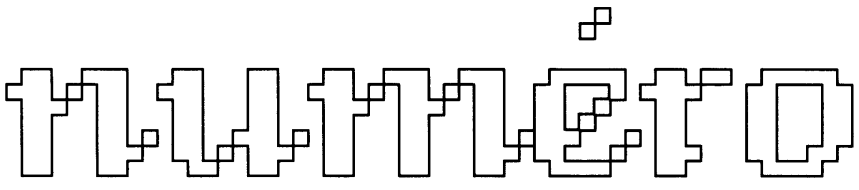

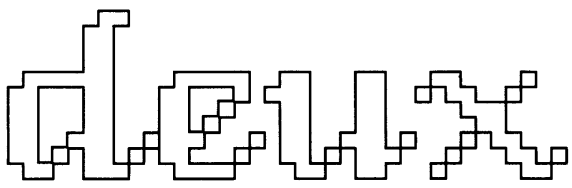


Si le premier numéro de muséologies Les cahiers d'études supérieures s'est révélé pour nous une aventure extrêmement positive, vos commentaires et vos appréciations auront largement contribué à ce que le numéro 2 soit constitué de façon à vous attirer encore plus nombreux à sa lecture. Nous avons fait pour muséologies le pari qu'aucune édition ne serait semblable à une autre, hormis la permanence d'articles de référence. Espérons que celle-ci et les subséquentes pourront confirmer cette règle.

Les articles ici colligés illustrent quelques applications de la muséologie actuelle et suggèrent tous un questionnement ultérieur. À la une de ce numéro 2, nous vous présentons en primeur l'article de Clara Ustinov, lauréate du prix RolandArpin 2006. Cet article, intitulé Quel musée pourl'art contemporain? expose la remise en question des institutions muséales face à la production artistique contemporaine et les relations paradoxales que ces milieux entretiennent. Symptomatique de la mutation muséale en cours, nous avons choisi de faire suivre cette analyse de la réflexion de PierreOlivier Ouellet. Son article juxtapose le phénomène de la transformation des musées et la place de plus en plus fragmentée de la recherche au sein de ceux-ci. La recherche appliquée, quant à elle, ne semble pas encore avoir perdu pied, du moins dans certains établissements : Audrey Boursaud évalue l'intention communicationnelle et la réception de l'exposition permanente Le Temps des Québécois au Musée de la civilisation. La diversification des offres culturelles ne s'éteint pas non plus : Ève-Marie Proulx nous présente l'univers éducationnel des jardins historiques du Québec.

Dans ce numéro 2, le volet de l'entrevue prend de l'expansion : trois membres de l'équipe de muséologies présentent des entretiens révélateurs de la pratique actuelle. En augmentant l'espace alloué à ce volet, saisir le qui fait quoi, le pourquoi et le comment enrichira le dialogue que nous tenons à constituer. Stéphanie Corriveau est allée à la rencontre de madame Louise Déry, directrice de la galerie de l'UQÀM, afin de recueillir ses propos sur le travail de commissariat et sur l'un des canaux de diffusion de l'art contemporain québécois, la galerie universitaire. Cela dit, nous saluons le fait que le Conseil des Arts du Canada ait choisi madame Déry lors d'une compétition nationale ouverte aux commissaires et aux conservateurs d'art contemporain canadiens pour représenter le pays en tant que commissaire à la Biennale de Venise 2007. Marie-Ève Courchesne s'est entretenue avec madame Colette Dufresne-Tassé, directrice du programme de muséologie à l'Université de Montréal. Madame Dufresne-Tassé, spécialiste de l'évaluation dans les institutions muséales, nous représente l'état actuel de cette pratique et de ses usages. Koliny Chhim a demandé à monsieur André Delisle, directeur du Musée du Château Ramezay, d'élaborer sur sa vision personnelle des jardins historiques au Québec et sur les techniques de médiation appliquées dans le Jardin du Gouverneur.

Ce tour d'horizon complété, je me permets à nouveau de réitérer l'invitation, que vous soyez professionnel ou universitaire, à proposer des articles, des comptes-rendus ou encore à nous soumettre vos commentaires. La mission de cette publication reste de créer une synergie entre le monde muséal et le milieu universitaire. L'équipe de muséologies croit cette association nécessaire et nous travaillerons à sa concrétisation. Il s'agit pour ceux et celles qui se sentent interpellés de s'approprier, pour un court laps de temps, cet espace de papier. N'hésitez pas, nous accueillerons vos propositions avec joie. - ALESSANDRA MARIANI 